\title{
REVIEW
}

\section{Aneurysmal subarachnoid haemorrhage from a neuroimaging perspective}

\author{
Airton Leonardo de Oliveira Manoel ${ }^{1,2,3^{*}}$, Ann Mansur ${ }^{3}$, Amanda Murphy ${ }^{4}$, David Turkel-Parrella ${ }^{2,5}$, Matt Macdonald ${ }^{6}$, \\ R Loch Macdonald ${ }^{3,5}$, Walter Montanera ${ }^{2,3}$, Thomas R Marotta ${ }^{2,3}$, Aditya Bharatha ${ }^{2,3}$, Khaled Effendi ${ }^{2}$ \\ and Tom A Schweizer ${ }^{3,7}$
}

\begin{abstract}
Neuroimaging is a key element in the management of patients suffering from subarachnoid haemorrhage (SAH). In this article, we review the current literature to provide a summary of the existing neuroimaging methods available in clinical practice. Noncontrast computed tomography is highly sensitive in detecting subarachnoid blood, especially within 6 hours of haemorrhage. However, lumbar puncture should follow a negative noncontrast computed tomography scan in patients with symptoms suspicious of SAH. Computed tomography angiography is slowly replacing digital subtraction angiography as the first-line technique for the diagnosis and treatment planning of cerebral aneurysms, but digital subtraction angiography is still required in patients with diffuse SAH and negative initial computed tomography angiography. Delayed cerebral ischaemia is a common and serious complication after SAH. The modern concept of delayed cerebral ischaemia monitoring is shifting from modalities that measure vessel diameter to techniques focusing on brain perfusion. Lastly, evolving modalities applied to assess cerebral physiological, functional and cognitive sequelae after $\mathrm{SAH}$, such as functional magnetic resonance imaging or positron emission tomography, are discussed. These new techniques may have the advantage over structural modalities due to their ability to assess brain physiology and function in real time. However, their use remains mainly experimental and the literature supporting their practice is still scarce.
\end{abstract}

\section{Introduction}

Aneurysmal subarachnoid haemorrhage (SAH) is caused by the rupture of an intracranial aneurysm, which leads to the extravasation of blood under high pressure into the subarachnoid space. SAH triggers a cascade of events that can result in death or severe disability. Poor outcomes are not uncommon, and are typically due to early brain injury associated with the initial haemorrhage or are secondary to delayed cerebral ischaemia (DCI) and cerebral infarction. This review will focus on the clinical applicability of neuroradiological tools applied to the diagnosis and management of $\mathrm{SAH}$, angiographic cerebral vasospasm (ACV), and DCI.

\footnotetext{
* Correspondence: airtonleo.manoel@gmail.com

${ }^{1}$ Trauma \& Neurosurgery Intensive Care, Department of Medical Imaging, 3-141 CC, St Michael's Hospital, University of Toronto, 30 Bond Street, Toronto, ON M5B 1 W8, Canada

${ }^{2}$ Medical Imaging, Interventional Neuroradiology, St Michael's Hospital, University of Toronto, 30 Bond Street, Toronto, ON M5B 1 W8, Canada Full list of author information is available at the end of the article
}

\section{Search strategy and selection criteria}

A PubMed search for articles published in English until April 2014 was performed using the terms 'subarachnoid hemorrhage [All Fields] OR subarachnoid haemorrhage [All Fields] OR cerebral aneurysm [All Fields] OR vasospasm [All Fields] OR cerebral vasospasm [All Fields] OR delayed cerebral ischemia [All Fields], which returned 84,357 articles (Additional file 1: Table S1). These articles were further distilled via prospective and retrospective studies, review articles, and meta-analyses addressing imaging features of $\mathrm{SAH}$, and their reference lists were also searched. The articles judged to be clinically relevant by the authors were selected. The methodological quality of the meta-analyses reviewed was assessed by the AMSTAR tool (Additional file 1: Table S2) [1]. Additionally, the references from the authors' personal database were retrieved and also used as a key source for this review. Lastly, the most recent guidelines on the management of SAH and their reference lists were also consulted and used to provide some of the clinical recommendations [2-4]. 


\section{Diagnosis of subarachnoid haemorrhage}

Headache is a common complaint, accounting for $2 \%$ of emergency department (ED) visits [5]. Although SAH represents a very small percentage of those patients admitted to the ED, it is a life-threatening condition that needs to be recognised and treated immediately. Failure to diagnose and treat SAH can lead to dire complications including aneurysm rebleeding, cerebral infarction, and ultimately death [6].

Misdiagnosis, defined as the failure to correctly recognise SAH at first contact between a patient and a medical professional, continues to occur and is associated with increased mortality and morbidity. In a large cohort of 482 SAH patients admitted to a tertiary university hospital, $12 \%$ of the cases were misdiagnosed according to the above definition [6]. The likelihood of a missed diagnosis was higher in patients with normal mental status because their symptoms could be misattributed to conditions such as migraine or tension headache, and less commonly to a viral syndrome, musculoskeletal pain, sinusitis, and hypertension [6]. Hence, it is not only imperative to have timely diagnosis, but also to employ the most appropriate and sensitive diagnostic modalities at first consultation in the ED.

The most common diagnostic error is the lack of noncontrast computed tomography (NCCT) ordered by the ED physician [6]. NCCT remains the first-line method for the diagnosis of SAH [3]. Evolving technology has rapidly improved the new generations of multidetector computed tomography (CT) scanners, making this equipment faster, less prone to motion artefacts, of better resolution, and possessing more accurate tools. The combination of this advanced technology with cuttingedge post-acquisition image processing software makes CT scanners more sensitive to detect subarachnoid blood. Additionally, CT is also highly available and affordable, making it the ideal screening modality for patients with suspected SAH.

In a retrospective study using a four-slice, four-detector CT scanner, Byyny and colleagues identified 149 patients with spontaneous SAH who presented to an academic tertiary care ED from 2001 to 2004 [7]. The sensitivity of NCCT for SAH was found to range from 90 to $95 \%$, causing the authors to conclude that NCCT has high sensitivity but should not be applied as a sole diagnostic modality in the diagnosis of SAH. Moreover, NCCT sensitivity decreases with time since haemorrhage; it has close to $100 \%$ sensitivity within 12 hours, 93\% within 1 day, and less than $60 \%$ within 1 week of haemorrhage [8].

A prospective, multicenter study included 11 tertiary EDs from 2000 to 2009 [9]. Using a third-generation CT scanner and imaging interpretation by an experienced neuroradiologist, the group enrolled 3,132 patients who were complaining of having 'the worst headache of their lives', of which 240 (7.7\%) had SAH. Although the overall sensitivity for SAH was only $92.9 \%$ (95\% confidence interval (CI), 89.0 to $95.5 \%$ ), all patients suffering from $\mathrm{SAH}$ were identified in the subgroup of 953 patients who were scanned within 6 hours of headache onset, thereby yielding sensitivity of $100 \%$ (95\% CI, 97.0 to $100.0 \%$ ), specificity of $100 \%$ ( $95 \%$ CI, 99.5 to $100 \%$ ), negative predictive value of $100 \%$ (95\% CI, 99.5 to $100 \%$ ) and positive predictive value of $100 \%$ ( $95 \%$ CI, 96.9 to $100 \%$ ). Additionally, in a retrospective study conducted in an academic Level 1 trauma centre, among the 177 patients who presented to the ED with headache and were scanned with a fifthgeneration CT scanner followed by a lumbar puncture (LP), no patients with negative NCCT results were diagnosed with SAH on LP [10].

Three possible pathways for the diagnosis of SAH have been described (Figure 1). Although the most invasive, NCCT followed by LP is the most validated pathway to rule out SAH [11]. NCCT combined with LP for patients with high clinical suspicion of SAH have close to $100 \%$ diagnostic sensitivity (95\% CI, 93.1 to 99.4\%) [10,12]. Ideally, cerebrospinal fluid analysis should be performed using spectrophotometry, which has the highest diagnostic accuracy among all cerebrospinal fluid analytical methods; however, this technique is not widely available [13].

The second described approach is the use of NCCT followed by computed tomography angiography (CTA). Some studies showed that negative CTA can rule out aneurysmal SAH in patients with severe headache and negative NCCT or perimesencephalic haemorrhage pattern $[14,15]$. The main disadvantages of this approach are the need for iodinated contrast and its potential for anaphylactic reaction and nephrotoxicity, but most importantly exposure to radiation.

The third approach is the use of magnetic resonance imaging (MRI) combined with magnetic resonance angiography (MRA). The fluid-attenuated inversion recovery MRI sequence is comparable with NCCT in detecting acute $\mathrm{SAH}$, and is clearly superior for subacute and chronic haemorrhage [16]. MRI is also a powerful tool in the differential diagnosis of intracranial pathologies, including tumours, inflammatory, and infectious processes.

In conclusion, negative NCCT might be enough to rule out $\mathrm{SAH}$ in patients presenting within 6 hours of headache onset. Patients presenting beyond the 6-hour mark require additional diagnostic testing if NCCT is negative $[3,4]$.

\section{Diagnosis of cerebral aneurysms}

Sensitivity and specificity for the detection of aneurysms >3 mm using CTA currently approach 100\%, and are comparable with digital subtraction angiography (DSA) [17-20]. Conventional CTA might be less sensitive and accurate than DSA for aneurysms $<3 \mathrm{~mm}$. However, recent 


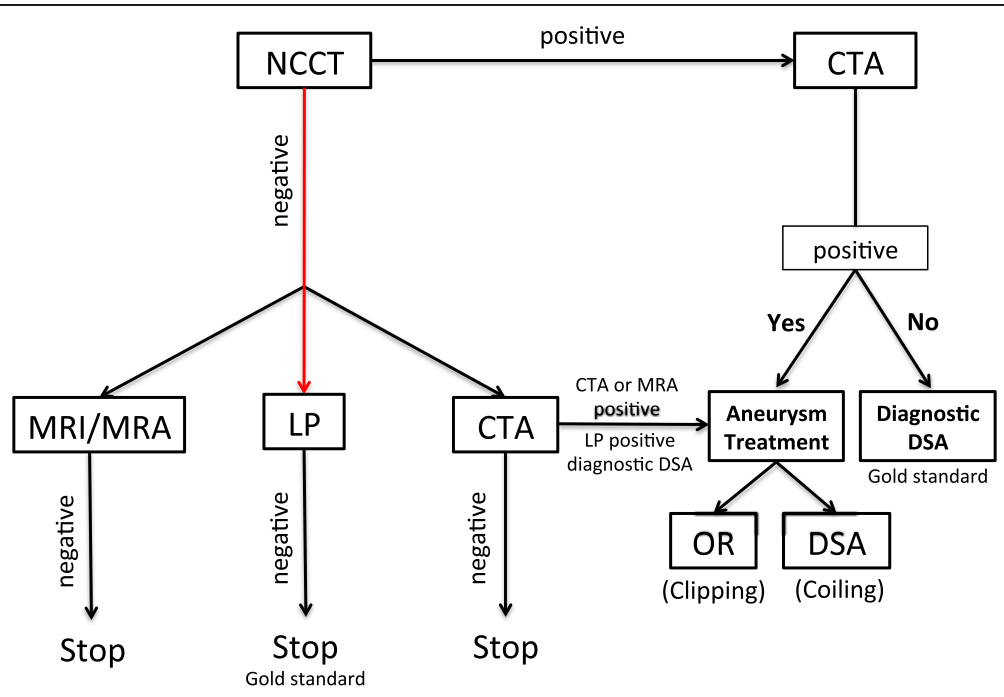

Figure 1 Diagnostic approach for subarachnoid haemorrhage in patients presenting with more than 6 hours of headache onset. CTA, computed tomography angiography; DSA, digital subtraction angiography; LP, lumbar puncture; MRA, magnetic resonance angiography; MRI, magnetic resonance imaging; NCCT, noncontrast computed tomography; OR, operating room.

data showed that CTA performed in a 64-row multislice scanner (sensitivity, specificity, and accuracy $96.3 \%, 100 \%$, and $98.5 \%$, respectively) [21] and subtraction CTA performed in a 320-detector row scanner (sensitivity, specificity, and accuracy $81.8 \%, 100 \%$, and $93.3 \%$, respectively) are highly accurate techniques to detect even aneurysms $<3 \mathrm{~mm}$ [22].

The high spatial and temporal resolution of DSA established this modality as the gold standard for cerebral aneurysm detection. However, DSA is invasive, costly, time-consuming, and demands expertise, limiting its use to a certain pool of medical professionals [23]. CTA may serve as an excellent alternative [2]. Two recent highquality meta-analyses (Additional file 1: Table S2) $[19,20]$ found CTA to be highly accurate $(97.2 \%$ sensitivity and 97.9\% specificity) in diagnosing cerebral aneurysms when compared with DSA.

DSA may still be required for treatment planning in complex aneurysms that include branching points of large vessels. However, modern CTA techniques, including subtraction CTA and three-dimensional reconstructions, can provide appropriate imaging even in complex cases (Figure 2). DSA is definitely required in patients with diffuse nonperimesencephalic SAH and negative initial CTA. In this specific situation, DSA should be performed to rule out small aneurysms $[7,14]$, and may be repeated within 2 to 6 weeks if the initial DSA is negative [24].

MRA is a possible alternative to CTA or DSA for aneurysm detection, especially in patients with iodine allergy. This modality does not expose the patients to radiation, and does not necessarily require gadolinium contrast injection. A recent published high-quality metaanalysis (Additional file 1: Table S2) including 12 studies
(960 patients assessed, 772 aneurysms) compared MRA with DSA as the gold standard for aneurysm detection. Most studies used time-of-flight sequences, which do not require contrast. The pooled MRA sensitivity and specificity were 95\% (95\% CI, 89 to 98\%) and 89\% (95\% CI, 80 to $95 \%$ ), respectively [25]. The main disadvantages of this modality are availability, costs, and the time consumed to acquire the images.

\section{Angiographic vasospasm and delayed cerebral ischaemia}

$\mathrm{ACV}$ is the narrowing of intracranial arteries detected by vascular imaging, while DCI is a syndrome defined as a focal neurological impairment, a decrease of at least 2 points on the Glasgow Coma Scale, or an increase of two points on the National Institutes of Health Stroke Scale that is not explained by other causes, such as hydrocephalus, rebleeding, or medical complications [26,27]. DCI is associated with higher rates of cerebral infarction, poor neurological outcome, and increased mortality $[3,4,28,29]$.

Historically, DCI occurring within 2 weeks of aneurysm rupture has been attributed to ACV. However, one-half of the patients with severe ACV $(>50 \%$ decrease in vessel diameter) will not develop DCI and up to $20 \%$ of patients without ACV (0 to $25 \%$ decrease in vessel diameter) will develop symptoms, which suggests that other factors besides $\mathrm{ACV}$ must play a role in the aetiology of DCI $[30,31]$.

\section{Transcranial Doppler ultrasonography}

Transcranial Doppler ultrasonography (TCD) is a noninvasive, reproducible, widely available technique that is 

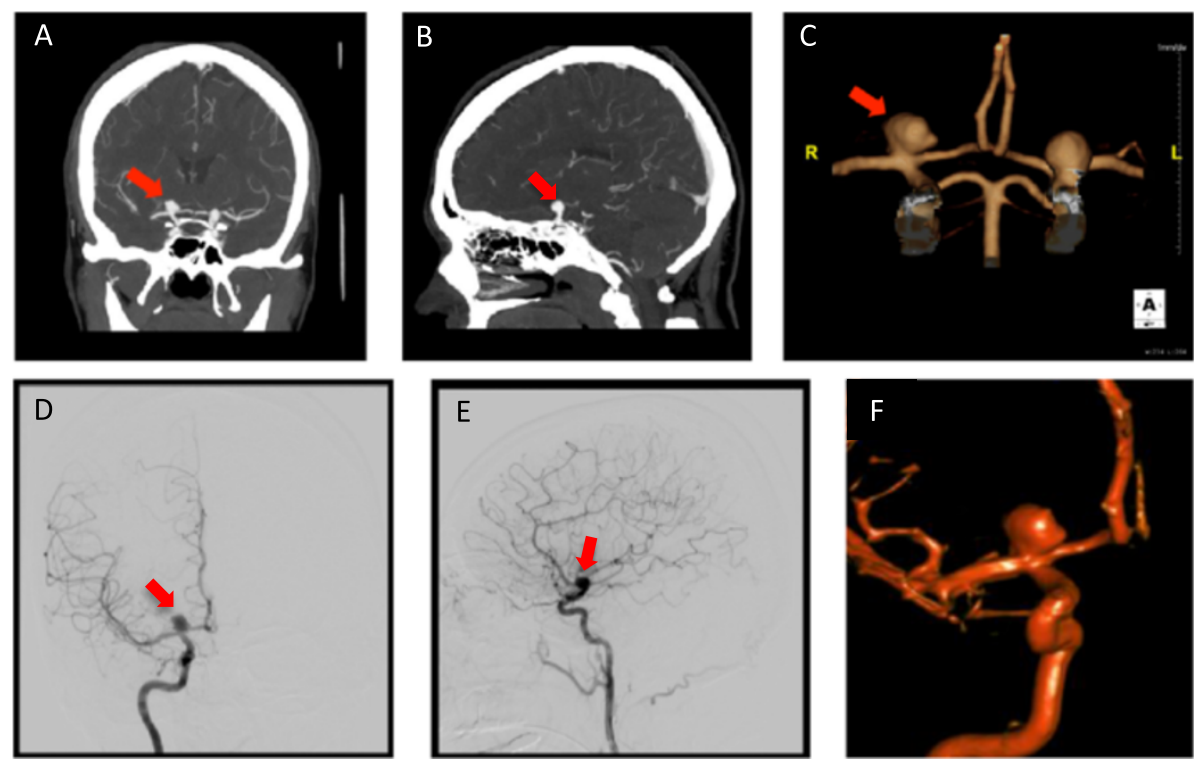

Figure 2 Computed tomography angiography and digital subtraction angiography. (A) to (C) Computed tomography angiography. (D) to (F) Digital subtraction angiography. Red arrow, right terminal internal carotid artery aneurysm. (A), (D) Coronal view. (B), (E) Sagittal view. (C), (F) Three-dimensional rendering.

commonly used to screen for ACV (Figures 3 and 4) $[3,32,33]$. This technique is based on the principle that the velocity of blood in a given artery is inversely proportional to the cross-sectional area of the artery. The mean middle cerebral artery (MCA) flow velocity is directly correlated to the degree of ACV by DSA [34] (Tables 1 and 2). A mean MCA flow velocity $\geq 120 \mathrm{~cm} /$ second or an increase $\geq 50 \mathrm{~cm} /$ second over a 24-hour period is consistent with ACV, and a mean MCA flow velocity $\geq 200 \mathrm{~cm} /$ second is diagnostic of severe ACV $[13,33]$.

The Lindegaard ratio (the ratio of MCA to extracranial portion of internal carotid artery mean flow velocity) is a useful way to differentiate $\mathrm{ACV}$ from cerebral hyperaemia (Table 2). Lindegaard ratio $<3$ is considered normal, while a ratio $\geq 6$ indicates severe ACV [33].

Several limitations of this technique should be mentioned: TCD is time consuming, is highly operator dependent, and requires experienced personnel to ensure consistent recordings. Up to $10 \%$ of patients, especially older women, do not demonstrate adequate acoustic windows [33]. More importantly, the accuracy for arteries other than the MCA is very poor. A high-quality metaanalysis [34] and a consensus statement [33] suggested that TCD is a useful tool to rule in vasospasm in the MCA, with high specificity and positive predictive value of $99 \%$ and $97 \%$, respectively. Other studies have reported high specificity (94 to $100 \%$ ) and variable sensitivity (39 to 96\%) when TCD was compared to DSA in the MCA [33]. Negative results should be interpreted with caution because they may represent a false negative result. Transcranial Doppler assessment of arteries other than the MCA is less useful, because of the low sensitivity and specificity [32].

\section{Multimodal computed tomography (NCCT + CTA + computed tomography perfusion)}

DCI is an exclusion diagnosis and can only be confirmed by imaging. Multimodal CT is frequently applied as a differential diagnostic tool at the moment of delayed neurological deterioration. NCCT is useful to exclude other causes of delayed neurological deterioration, such as hydrocephalus, rebleeding, or cerebral oedema. CTA is a good non-invasive alternative to DSA for diagnosing ACV (Figure 5A) [32]. Both techniques have a high degree of correlation for proximal ACV (agreement between 92 and 95\%) [35,36]. However, the ability to monitor regional cerebral blood flow (CBF) and to assess global and regional cerebral perfusion is the main recent advance in DCI monitoring. Computed tomography perfusion (CTP) can be performed as a component of multimodal CT scanning (Figure $5 \mathrm{~B}, \mathrm{C}$ ). The combination of CTA/CTP is more sensitive for ACV than TCD [33] and DSA [37].

Two high-quality meta-analyses that were recently published included 15 studies with 915 patients [38,39]. The first meta-analysis included studies that defined DCI as: clinical deterioration not explained by other causes; cerebral infarction on follow-up CT or MRI; and functional disability related to DCI. The results showed that SAH patients with perfusion changes measured by CTP had 23 times higher odds of having DCI than patients with normal CTP parameters (odds ratio, 23.14; 95\% CI, 5.87 to 91.19$)$. The pooled sensitivity and specificity of 


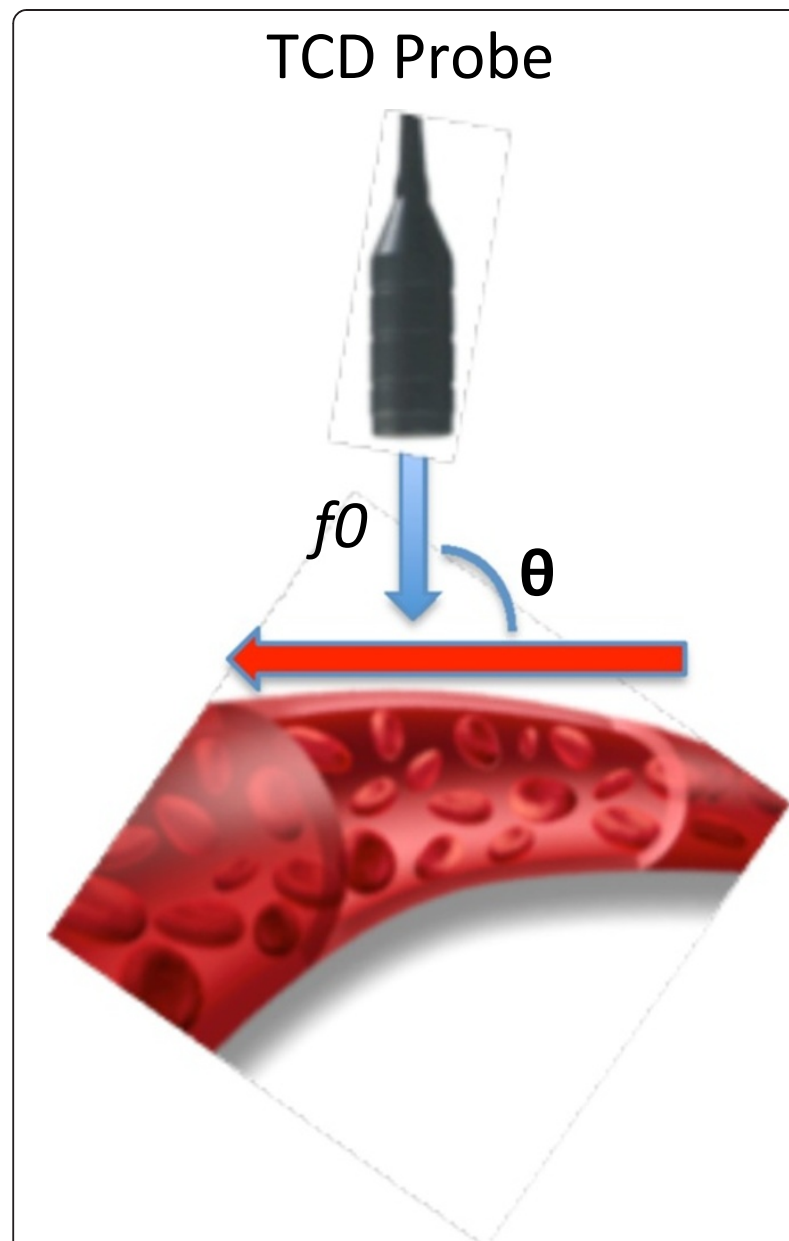

Figure 3 Technical aspects. Transcranial Doppler ultrasonography (TCD) probe emits low-frequency (2 MHz), pulsed waves that cross the skull at specific points called acoustic windows. The emitted waves are reflected back from the moving red blood cells at an altered frequency fe. The Doppler effect ( $f e$ ) is the difference in frequency between the transmitted wave $f 0$ and the received wave $f e: f d=f e-f 0$. The red blood cells' velocity can then be calculated according to the following mathematic equation: $V=c \times f d / 2 \times$ $f 0 \times \cos \theta$. $\theta$ is the angle formed by the ultrasound beam and the blood flow. Ideally this angle should approach $0^{\circ}$ so that the ultrasound beam is parallel to the blood flow $\left(\cos 0^{\circ}=1\right)$. The higher this angle, the lower the velocity read by the machine. If the ultrasound beam is perpendicular to the blood flow, no velocity will be detected $\left(\cos 90^{\circ}=0\right)$. This concept is fundamental to the performance and interpretation of TCD results. The velocities can be underestimated, never overestimated.

CTP for DCI were 0.84 (95\% CI, 0.7 to 0.95 ) and 0.77 (95\% CI, 0.66 to 0.82 ), respectively [40-45].

The second meta-analysis included original prospective and retrospective articles that reported data on the relationship between DCI (defined by clinical symptoms) and CTP. Perfusion parameters (CBF, mean transit time, time to peak, cerebral blood volume) were measured by either a quantitative method (comparing perfusion parameters in a given part of the brain with the same contralateral area) or a qualitative method (visual inspection of affected hemisphere compared with the contralateral side). The included studies were divided into two categories: CTP performed within 72 hours of haemorrhage (CTP as a predictor of $\mathrm{DCI}$ ), and CTP performed between days 4 and 14 after SAH (CTP as a diagnostic tool for DCI). Early CTP parameters ( $<72$ hours of SAH) were not predictive of DCI, but an increased mean transit time (pooled mean difference, 1.5 seconds; $95 \%$ CI, 0.9 to 2.2 ) or decreased CBF (difference, $-11.9 \mathrm{ml} / 100 \mathrm{~g} /$ minute; 95\% CI, -15.2 to -8.6 ) in the CTP performed between day 4 and day 14 was diagnostic for DCI [41,44,46-54].

In summary, the use of multimodal CT may be useful in the differential diagnosis of delayed neurological deterioration. Mean transit time and CBF values can distinguish between patients with and without DCI. However, the absolute thresholds may differ depending on the scanner and the post-processing methods applied.

\section{Short-term and long-term follow-up imaging after aneurysm treatment}

\section{Intraoperative angiography}

Perioperative imaging is useful to detect complications during and immediately after surgical clipping. Tang and colleagues evaluated the use of intraoperative angiography (IOA) performed during 517 consecutive craniotomies for aneurysm clipping [55]. In $12.4 \%$ of the cases, IOA findings resulted in surgical treatment change. Residual aneurysm (47\%) and vessel flow compromise (44\%) were the two most common causes of treatment change prompted by IOA. Aneurysms located in the internal carotid artery or giant aneurysms $(>24 \mathrm{~mm})$ were the two factors independently associated with treatment revision. Other case series have described similar results [56].

\section{Long-term follow-up}

The international SAH trial of neurosurgical clipping versus endovascular coiling (International Subarachnoid Aneurysm Trial) followed patients with SAH for a mean period of 9 years after treatment [57]. Patients treated by endovascular coiling have a $23 \%$ relative risk reduction and a $7.4 \%$ absolute risk reduction in death and dependence [58]; however, this is at a cost of significantly higher rates of rebleeding $(2.5 \%$ vs. $1 \%)$ and a need for late retreatment (6.9 times higher rate) [59]. The main determinant of postoperative rebleeding risk is whether or not the aneurysm is completely excluded from the cerebral circulation (Figure 6).

After endovascular treatment, the mean time to late retreatment (that is, $>3$ months after coiling or 1 month after clipping) was 20.7 months (range, 3 to 80 months) versus 5.7 months in the clipped group. Younger patients ( $<40$ years old), larger aneurysms $(\geq 11 \mathrm{~mm})$, and incomplete occlusion (Additional file 1: Table S3) are the main 


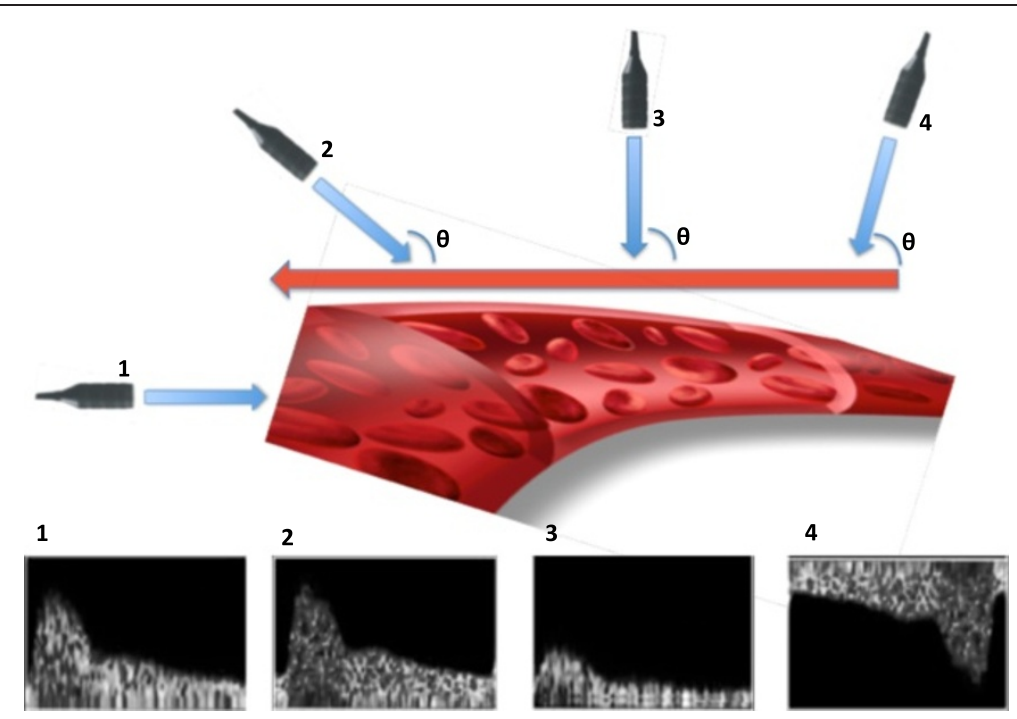

Figure 4 Effect of the angle between the ultrasound beam and blood flow. (1) Ultrasound beam is parallel to blood flow, acquiring an optimal, high-frequency Doppler signal. (2) Ultrasound beam forms an angle $<20^{\circ}$, leading to a good signal. (3) Ultrasound beam is almost at $90^{\circ}$, resulting in a damped waveform. (4) Blood flow direction is away from ultrasound beam, which results in a negative Doppler signal.

risk factors for retreatment after coiling [59,60]. Longterm follow-up imaging is therefore usually required to detect aneurysm recurrences, especially after coiling [59].

MRA may be an attractive alternative to DSA in the setting of post-coiling follow-up (Figure 7). MRA is noninvasive, usually does not require contrast, and does not expose the patient to radiation.

van Amerongen and colleagues performed a highquality systematic review and meta-analysis of 26 studies comparing MRA with DSA for follow-up of coiled aneurysms [61]. Both time-of-flight and contrast-enhanced MRA were highly accurate. The pooled time-of-flight MRA sensitivity and specificity were $86 \%$ and $84 \%$, respectively; similarly contrast-enhanced MRA had $86 \%$ sensitivity and $89 \%$ specificity.

Even though aneurysm recurrence after clipping is less frequent, imaging follow-up is still required. Multiple studies comparing postoperative CTA versus DSA have been published with similar results [62-68]. Multidetector CTA is highly sensitive and specific for residual aneurysm detection and parent vessel occlusion, and might be a valuable diagnostic alternative to DSA. However, DSA might still be required for aneurysm with multiple clips $[67,69]$, for neck remnant detection [68], or for aneurysms located in the posterior circulation [63].

The main concern with the use of postoperative CTA for aneurysm follow-up is the image quality, which can be compromised by clip-generated artefacts (Figure 5F) [64]. The factors associated with CTA image quality include the clip material (cobalt is worse than titanium alloy clips) [69,70], clip orientation (within the scan plane), and the number of clips on the same aneurysm $[64,69]$. Metal artefact reduction algorithms using flatpanel detector CT [71,72], subtraction three-dimensional CTA with the orbital synchronised helical scan technique [65], and advanced 3 T MRI imaging techniques [73] are some of the new modalities applied to reduce artefacts generated by the metallic clips, which can in turn improve the quality of the image.

In summary, patients treated by either surgical clipping or endovascular coiling should be followed after aneurysm occlusion [59]. Ideally, IOA should be performed to detect complications during surgical clipping. After endovascular coiling, the postoperative surveillance by either DSA or

Table 1 Transcranial Doppler characteristics

\begin{tabular}{|c|c|c|c|c|}
\hline Artery & Window & Depth (mm) & Direction of flow & Mean flow velocity $(\mathrm{cm} / \mathrm{second})$ \\
\hline Middle cerebral & Temporal & 40 to 60 & Toward probe & $55 \pm 12$ \\
\hline Anterior cerebral & Temporal & 60 to 85 & Away from probe & $50 \pm 11$ \\
\hline Posterior cerebral & Temporal & 60 to 70 & Toward & $40 \pm 10$ \\
\hline Extracranial internal carotid & Submandibular & 50 & Away & $28 \pm 17$ \\
\hline Vertebral & Occipital & 60 to 80 & Away & $38 \pm 10$ \\
\hline Basilar & Occipital & 80 to 120 & Away & $41 \pm 10$ \\
\hline
\end{tabular}


Table 2 Middle cerebral artery criteria of angiographic vasospasm by transcranial Doppler ultrasonography

\begin{tabular}{lll}
\hline & $\begin{array}{l}\text { Mean flow velocity } \\
\text { (cm/second) }\end{array}$ & $\begin{array}{l}\text { Hemispheric ratio } \\
\text { (Lindegaard ratio) }\end{array}$ \\
\hline Normal values & 35 to 89 & $<3$ \\
Above normal values & 90 to 119 & - \\
Mild vasospasm & 120 to 150 & 3 to 4 \\
Moderate & 150 to 199 & 4 to 5.9 \\
Severe & $\geq 200$ & $\geq 6$ \\
\hline
\end{tabular}

MRA is recommended. MRA with either time-of-flight or contrast-enhanced sequences may be the modality of choice. Clipped aneurysms can be followed by the use of CTA, but DSA should be performed if clip artefacts prevent adequate image interpretation. The time interval between images and duration of follow-up remain unclear.

\section{Future directions}

Several emerging imaging modalities are currently available for research purposes, such as magnetic resonancebased images (including functional MRI) and positron emission tomography (PET). In the near future, these evolving fields of neuroimaging may serve as important tools when choosing treatment options and predicting functional and cognitive recovery after SAH.

\section{Magnetic resonance-based modalities Structural magnetic resonance imaging}

Structural damage caused by the primary haemorrhage, treatment, or DCI is not infrequent after SAH, and can ultimately lead to neuropsychological deficits and cognitive impairment. MRI can identify these structural changes $[74,75]$. Parenchymal high-signal intensity lesions detected on T2-weighted and intermediate-weighted images, and low signal intensity on three-dimensional T1-weighted images can represent a variety of aetiologies such as ischaemic lesions, residual haematoma, retraction injury due to surgical manipulation and instrumentation, lesions associated with external ventricular drains (Figure 5E) or permanent shunt placement, and previous infarctions. These high-signal intensity lesions are more frequent after surgical clipping and the lesion volume correlates with neuropsychological test performance [76].
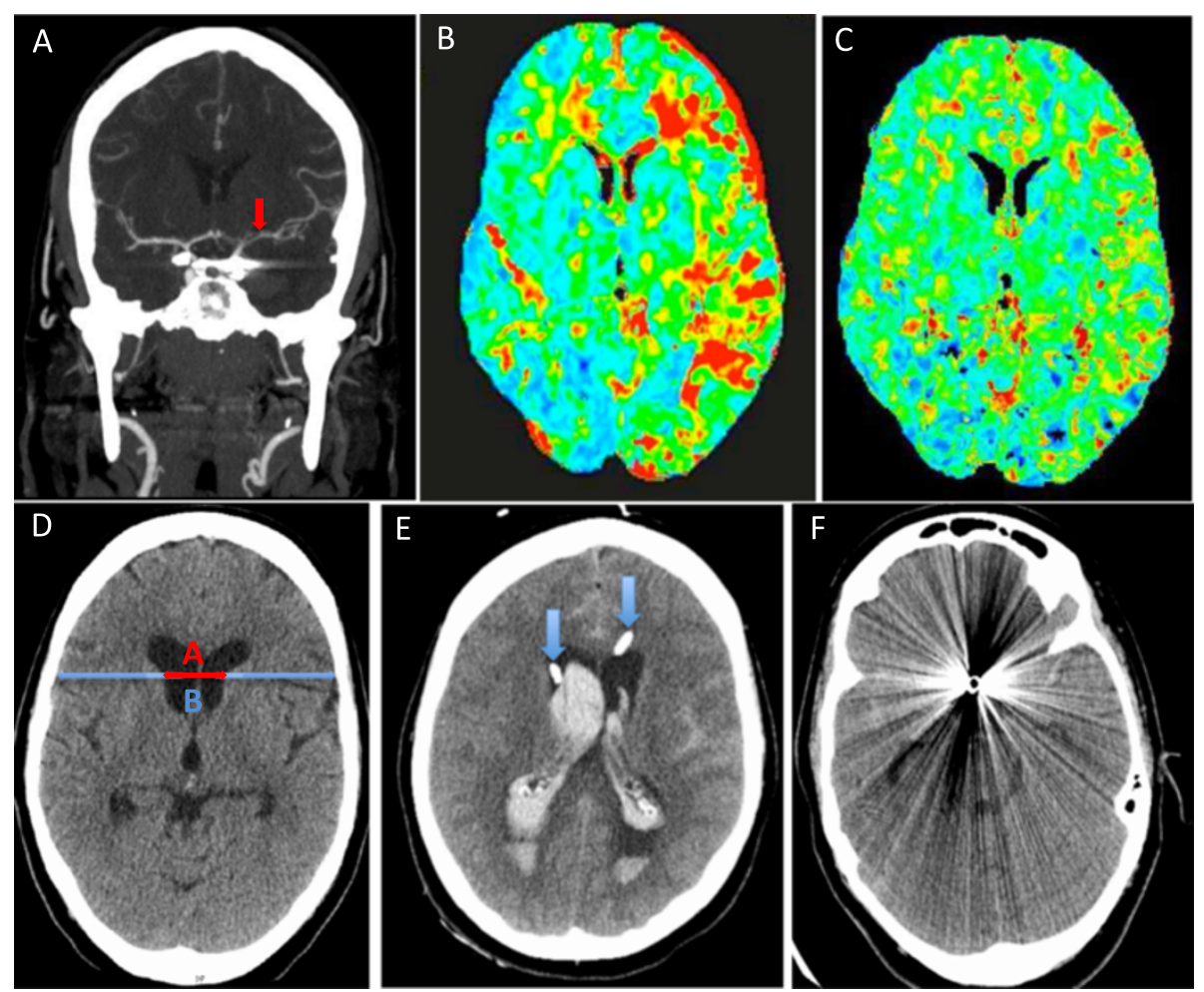

Figure 5 Multimodal computed tomography. (A) Computed tomography (CT) angiography (coronal plane) shows severe angiographic vasospasm in the left middle cerebral artery (MCA; red arrow). (B) CT perfusion displays increased mean transit time (increased shades of red in the left hemisphere) due to MCA vasospasm. (C) Same patient, CT perfusion repeated after 48 hours of haemodynamic augmentation, which shows resolution of perfusion changes. (D) Noncontrast computed tomography (NCCT) showing the measurement of bicaudate index (A/B) as proposed by van Gijn and colleagues [98]. (E) NCCT shows large volume of intraventricular haemorrhage. The tip of the bilateral external ventriculostomy drains can be seen in the anterior horn of the lateral ventricles (blue arrows). (F) NCCT quality severely compromised by artefacts generated by the metallic colis. 


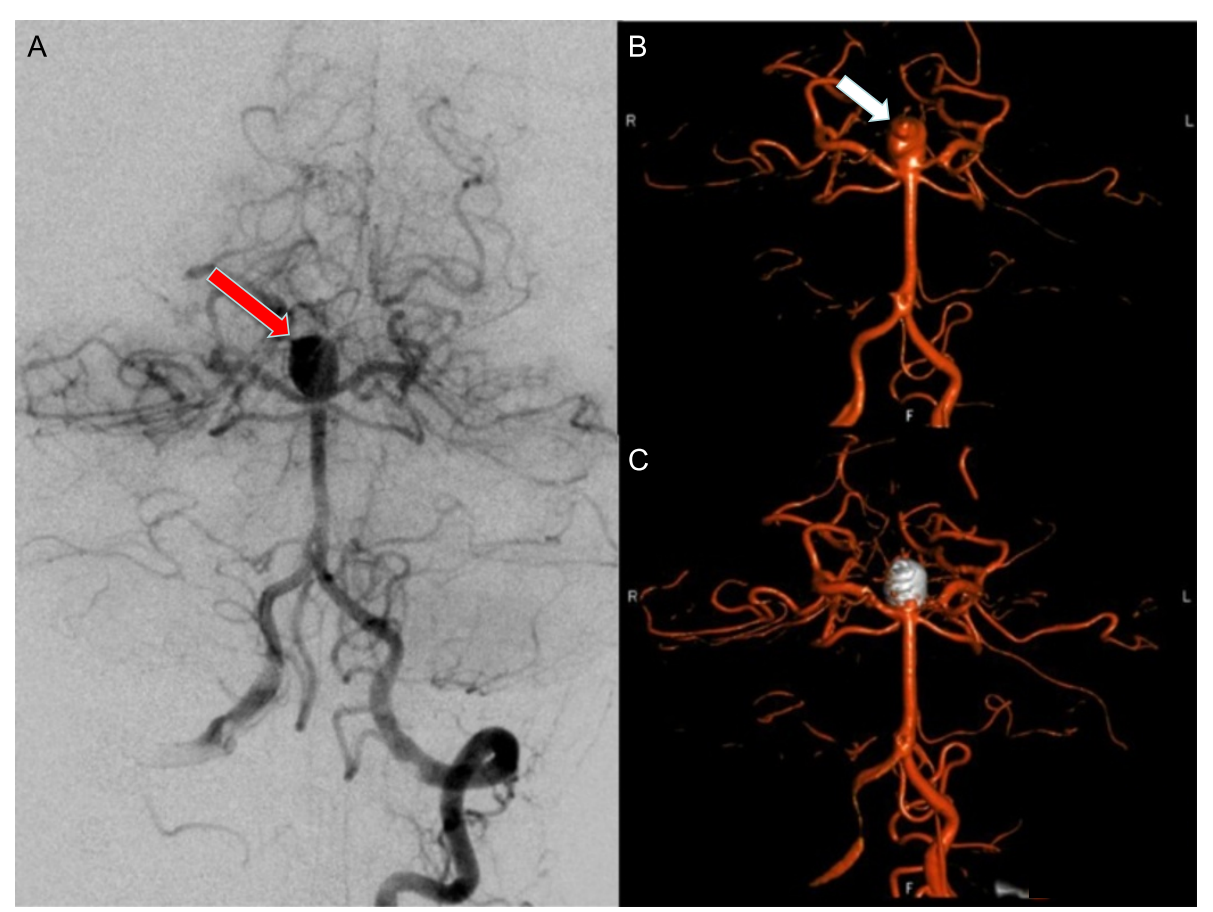

Figure 6 Digital subtraction angiography. (A) Selective left vertebral artery injection shows a basilar tip aneurysm (red arrow). (B) The same basilar tip aneurysm (white arrow), now appreciated through a three-dimensional rendering. (C) The gray structure is the mass of coils packing the previous basilar tip aneurysm. Final results show a complete obliteration of the aneurysm's sac after the endovascular coiling.

\section{Magnetic resonance imaging morphometry}

The measurement of temporomesial volume by volumetric MRI (the protocol includes T2-weighted and proton density-weighted images, MRA, and three-dimensional T1-weighted sequences) [77], especially the hippocampal formation, can provide important information on cognitive performance [78]. Lesions affecting the bilateral medial temporal lobes typically lead to severe memory deficits. Unilateral lesions in the dominant hemisphere can cause deficits in verbal memory, while unilateral lesions in the nondominant hemisphere can cause visual-spatial memory loss. Aneurysmal SAH was shown to be associated with temporomesial atrophy, especially after surgical clipping [76]. Temporomesial volume loss is correlated with neuropsychological impairment, which includes memory deficits [78].

Bendel and colleagues examined the impact of brain structure volume changes on neurocognitive performance by evaluating the MRI scans of 138 patients that were randomly assigned to surgical versus endovascular treatment 1 year after the haemorrhage. Reduced hippocampal volume correlated with poor score on several measures of cognitive function such as visual memory, attention, flexibility of mental processing, intellectual ability, and psychomotor speed [78]. These deficits are more pronounced in patients who have combined decreased hippocampal volume and frontal lobe lesions, and are more common after surgical clipping than endovascular coiling [79].
The same group described the relationship of global cerebral atrophy and cognitive deficit after SAH [80]. Seventy-six patients (1 year after haemorrhage) and 30 healthy controls underwent MRI (T2-weighted and proton attenuation-weighted images, and three-dimensional T1-weighted images needed for volumetry). The cerebrospinal fluid/total intracranial volume ratio was quantified by statistical parametrical mapping, and was statistically higher in SAH patients and correlated with clinical outcome (that is, Glasgow outcome scale) and cognitive deficit.

\section{Diffusion-weighted imaging}

Diffusion-weighted imaging identifies tissues at risk for ischaemia by detecting restriction to water diffusion. Diffusion-weighted imaging is a potent instrument for the detection of early brain injury after SAH [81], presenting higher sensitivity compared to NCCT $[82,83]$. Diffusion-weighted imaging may predict functional outcome after poor-grade SAH $[84,85]$. In a very elegant study, Sato and colleagues included 38 poor-grade SAH patients that were treated aggressively. Lesions $>10 \mathrm{~mm}$ on diffusion-weighted imaging scans performed within 24 hours of haemorrhage were predictive of poor outcome (severe disability, vegetative state or death). The authors attributed these lesions to primary brain damage (that is, haemorrhage) [84]. This hypothesis of early brain ischaemia has been supported by recent work that showed 


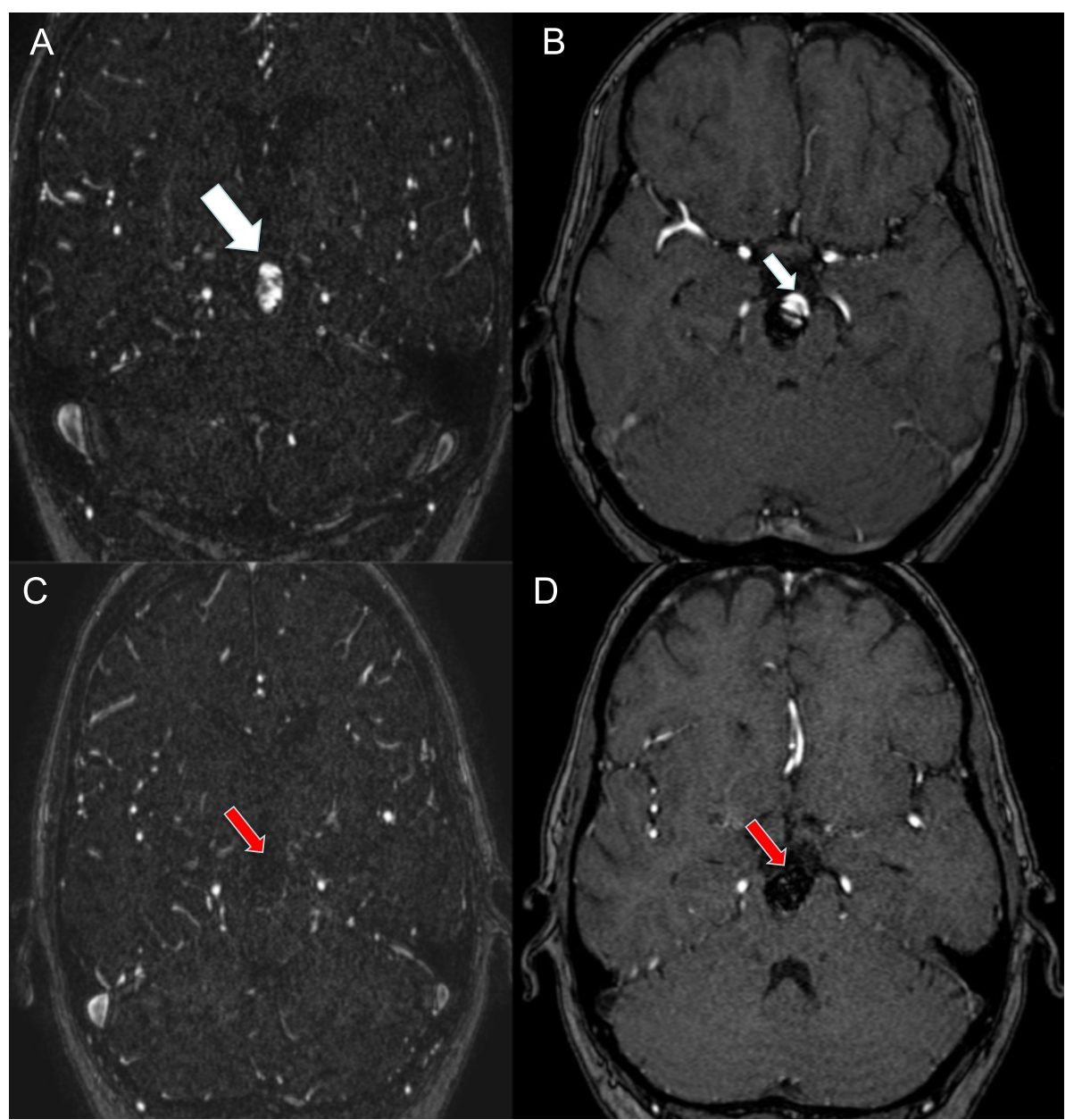

Figure 7 Magnetic resonance angiography. (A) Contrast-enhanced (CE) magnetic resonance angiography (MRA) sequence showing recanalisation of a previously coiled basilar tip aneurysm (large white arrow). (B) Time-of-flight MRA sequence revealing the refilling of the same basilar tip aneurysm (small white arrow). (C) CE-MRA and (D) time-of-flight MRA sequences after retreatment. No additional filling of the aneurysm is seen (red arrows).

early infarct volume measured by diffusion-weighted imaging/apparent diffusion coefficient correlated with death or severe disability (adjusted odds ratio, 1.7; 95\% CI, 1.0 to 3.2; $P=0.066)[86]$.

\section{Functional magnetic resonance imaging}

Functional MRI is a neuroimaging modality that measures brain activity by detecting changes in CBF. The modality was first described by Seiji Ogawa, using what he called blood oxygen level-dependent contrast [87]. This technique assumes that CBF is coupled with neuronal activation; therefore, CBF increases towards a given brain region that is in use.

Functional MRI represents a possible step towards our capability of prognosticating patients suffering from acute brain injury, including ischaemic stroke [88], intracerebral haemorrhage [89], and SAH [90]. This modality has a potential advantage over structural modalities by being able to assess brain function in real time. However, its use remains largely experimental.

The functional MRI literature in the SAH population is very scant. In a single prospective study, $11 \mathrm{SAH}$ patients and 10 healthy subjects underwent functional MRI while performing verbal working memory tasks. Patients performed worse than healthy individuals (percent correct $82.9 \%$ vs. $97.5 \%, P<0.003$ ). The memory impairment was accompanied by a relatively increased blood oxygen level-dependent signal in widespread bilateral cortical areas. The authors hypothesised that 'deficits in verbal working memory following recovery from SAH are accompanied by widespread differences in hemodynamic correlates of neural activity. These differences are discussed with respect to the immediate and delayed focal and global brain damage that can occur following $\mathrm{SAH}$, and the possibility that this damage induces subcortical disconnection and subsequent decreased efficiency in neural processing' [90]. 


\section{Positron emission tomography}

PET is a modality that maps perfusion and physiological activity by the use of exogenous radioactive compounds that are injected systemically. PET records and interpolates anatomical regions of the brain through detection of electromagnetic radiation; it also measures global and regional $\mathrm{CBF}$, and also the oxygen delivery to cerebral tissues, which are important endpoints for DCI monitoring [91-94].

Over the last decade, a group from the Washington University School of Medicine led by Dr Diringer has conducted a series of experiments to determine the optimal haemodynamic intervention that would improve cerebral oxygen delivery in a setting of DCI. In the first experiment, the authors examined the effects of a normal saline fluid bolus on regional and global CBF, measured by PET. Six SAH patients who developed DCI underwent PET scanning before and after a normal saline bolus of $15 \mathrm{ml} / \mathrm{kg}$ administered over 1 hour. The fluid bolus was associated with increased CBF in hypoperfused regions of the brain [95]. In the second experiment, eight anaemic $(<10 \mathrm{~g} / \mathrm{dl})$ SAH patients underwent PET scanning before and after the transfusion of 1 unit of red blood cells. Blood transfusion was associated with increased cerebral oxygen delivery in areas of ischaemia, reduction of oxygen extraction fraction, and no change in global CBF [96].

In the last published experiment, the authors compared the effect of a saline fluid bolus of $15 \mathrm{ml} / \mathrm{kg}$, of induced hypertension by increasing mean arterial pressure by $25 \%$, and of the transfusion of 1 unit of red blood cells [97]. Regional and global CBF, as well as oxygen delivery, were measured by PET imaging in $38 \mathrm{SAH}$ patients that developed DCI. All three methods increased regional oxygen delivery from baseline, but red blood cell transfusion to anaemic patients (haemoglobin $<9.0 \mathrm{~g} / \mathrm{dl}$ ) performed better than both hypertension and volume loading as a haemodynamic intervention in reducing the ischaemic burden.

Despite the interesting conclusions drawn from those studies, the utility of PET remains limited to research. The required isotopes are very expensive and restricted to major centres, thus limiting the technique's clinical applications.

\section{Conclusion}

Neuroimaging is a fundamental component in the management of patients suffering from SAH. NCCT might be sufficient to rule out SAH if performed within 6 hours of headache onset. However, patients presenting beyond the 6-hour mark with symptoms suspicious for SAH and negative NCCT should undergo LP. The combinations of NCCT and CTA or MRI and MRA are at least as sensible as the classic NCCT and LP approach, and can be used to rule out SAH. CTA is slowly replacing DSA as the first-line technique for the diagnosis and treatment planning of cerebral aneurysms, but DSA is still required in patients with diffuse SAH and initially negative CTA. The modern concept of DCI monitoring is shifting from modalities used to detect angiographic vasospasm to techniques focusing on brain perfusion, such as CTP. Lastly, new modalities applied to assess cerebral physiological, functional, and cognitive outcome after SAH are rapidly evolving; however, their use remains experimental.

\section{Additional file}

Additional file 1: The following additional data are available with the online version of this paper. Additional file 1 is Table S1 presenting PubMed search criteria, Table S2 presenting methodological quality of meta-analyses, and Table S3 presenting the degree of aneurysm occlusion.

\section{Abbreviations}

ACV: Angiographic cerebral vasospasm; CBF: Cerebral blood flow; Cl: Confidence interval; CT: Computed tomography; CTA: Computed tomography angiography; CTP: Computed tomography perfusion; DCI: Delayed cerebral ischaemia; DSA: Digital subtraction angiography; ED: Emergency department; IOA: Intraoperative angiography; LP: Lumbar puncture; MCA: Middle cerebral artery; MRA: Magnetic resonance angiography; MRI: Magnetic resonance imaging; NCCT: Noncontrast computed tomography; PET: Positron emission tomography;

SAH: Subarachnoid haemorrhage; TCD: Transcranial Doppler ultrasonography.

\section{Competing interests}

RLM receives grant support from Actelion Pharmaceuticals Ltd, and is a stockholder of Edge Therapeutics; he is also a consultant for Actelion Pharmaceuticals Ltd. TRM is the inventor of, and has patents for, the endovascular clip system (eCLIPs). The remaining authors declare that they have no competing interests.

\section{Authors' contributions}

ALdOM, AMa, TAS, and RLM formed the conceptual framework for this article. ALdOM, AMa, MM, and AMu conducted the literature search. ALdOM, RLM, WM, TRM, and AB provided evaluations of the clinical significance of the screened articles. ALdOM, DT-P, and KE were responsible for the images and tables. DT-P and KE screened and analysed all the meta-analyses using AMSTAR [1]. All authors contributed to the drafting, revising and approval of the final manuscript.

\section{Acknowledgements}

This work was supported by a Personnel Award from the Heart and Stroke Foundation of Canada and an Early Researcher Award from the Ontario Ministry of Research and Innovation to TAS. The authors would also like to thank the Bitove Foundation for generously funding the research.

\section{Author details}

${ }^{1}$ Trauma \& Neurosurgery Intensive Care, Department of Medical Imaging, 3-141 CC, St Michael's Hospital, University of Toronto, 30 Bond Street, Toronto, ON M5B 1 W8, Canada. ${ }^{2}$ Medical Imaging, Interventional Neuroradiology, St Michael's Hospital, University of Toronto, 30 Bond Street, Toronto, ON M5B 1 W8, Canada. ${ }^{3}$ Keenan Research Centre of the Li Ka Shing Knowledge Institute of St Michael's Hospital, 30 Bond Street, Toronto, ON M5B 1 W8, Canada. ${ }^{4}$ Medical Imaging, University of Toronto, 30 Bond Street, Toronto, ON M5B 1 W8, Canada. ${ }^{5}$ Division of Neurosurgery, St Michael's Hospital, University of Toronto, 30 Bond Street, Toronto, ON M5B 1 W8, Canada. ${ }^{6}$ Faculty of Medicine, University of Toronto, 30 Bond Street, Toronto, ON M5B 1 W8, Canada. ${ }^{7}$ Neuroscience Research Program, St Michael's Hospital, University of Toronto, 30 Bond Street, Toronto, ON M5B 1 W8, Canada.

Published online: 13 November 2014 


\section{References}

1. Shea BJ, Grimshaw JM, Wells GA, Boers M, Andersson N, Hamel C, Porter AC, Tugwell P, Moher D, Bouter LM: Development of AMSTAR: a measurement tool to assess the methodological quality of systematic reviews. BMC Med Res Methodol 2007, 7:10

2. Diringer MN, Bleck TP, Claude Hemphill J 3rd, Menon D, Shutter L, Vespa $P$, Bruder N, Connolly ES Jr, Citerio G, Gress D, Hänggi D, Hoh BL, Lanzino G, Le Roux P, Rabinstein A, Schmutzhard E, Stocchetti N, Suarez II, Treggiari M, Tseng MY, Vergouwen MD, Wolf S, Zipfel G, Neurocritical Care Society: Critical care management of patients following aneurysmal subarachnoid hemorrhage: recommendations from the Neurocritical Care Society's multidisciplinary consensus conference. Neurocrit Care 2011, 15:211-240.

3. Connolly ES Jr, Rabinstein AA, Carhuapoma JR, Derdeyn CP, Dion J, Higashida RT, Hoh BL, Kirkness CJ, Naidech AM, Ogilvy CS, Patel AB, Thompson BG, Vespa P: Guidelines for the management of aneurysmal subarachnoid hemorrhage: a guideline for healthcare professionals from the American Heart Association/American Stroke Association. Stroke 2012, 43:1711-1737.

4. Steiner T, Juvela S, Unterberg A, Jung C, Forsting M, Rinkel G: European Stroke Organization quidelines for the management of intracranial aneurysms and subarachnoid haemorrhage. Cerebrovasc Dis 2013, 35:93-112.

5. Edlow JA, Panagos PD, Godwin SA, Thomas TL, Decker WW: Clinical policy: critical issues in the evaluation and management of adult patients presenting to the emergency department with acute headache. Ann Emerg Med 2008, 52:407-436.

6. Kowalski RG, Claassen J, Kreiter KT, Bates JE, Ostapkovich ND, Connolly ES, Mayer SA: Initial misdiagnosis and outcome after subarachnoid hemorrhage. JAMA 2004, 291:866-869.

7. Byyny RL, Mower WR, Shum N, Gabayan GZ, Fang S, Baraff L: Sensitivity of noncontrast cranial computed tomography for the emergency department diagnosis of subarachnoid hemorrhage. Ann Emerg Med 2008, 51:697-703.

8. van Gijn J, van Dongen KJ: The time course of aneurysmal haemorrhage on computed tomograms. Neuroradiology 1982, 23:153-156.

9. Perry JJ, Stiell IG, Sivilotti ML, Bullard MJ, Emond M, Symington C, Sutherland J, Worster A, Hohl C, Lee JS, Eisenhauer MA, Mortensen M, Mackey D, Pauls M, Lesiuk H, Wells GA: Sensitivity of computed tomography performed within six hours of onset of headache for diagnosis of subarachnoid haemorrhage: prospective cohort study. BMJ 2011, 343:d4277.

10. Boesiger BM, Shiber JR: Subarachnoid hemorrhage diagnosis by computed tomography and lumbar puncture: are fifth generation CT scanners better at identifying subarachnoid hemorrhage? J Emerg Med 2005, 29:23-27.

11. Perry JJ, Spacek A, Forbes M, Wells GA, Mortensen M, Symington C, Fortin N, Stiell IG: Is the combination of negative computed tomography result and negative lumbar puncture result sufficient to rule out subarachnoid hemorrhage? Ann Emerg Med 2008, 51:707-713.

12. Gee C, Dawson M, Bledsoe J, Ledyard H, Phanthavady T, Youngquist $\mathrm{S}$, McGuire T, Madsen T: Sensitivity of newer-generation computed tomography scanners for subarachnoid hemorrhage: a Bayesian analysis. $J$ Emerg Med 2012, 43:13-18.

13. Nagy K, Skagervik I, Tumani H, Petzold A, Wick M, Kühn HJ, Uhr M, Regeniter A, Brettschneider J, Otto M, Kraus J, Deisenhammer F, Lautner R, Blennow K, Shaw L, Zetterberg H, Mattsson N: Cerebrospinal fluid analyses for the diagnosis of subarachnoid haemorrhage and experience from a Swedish study. What method is preferable when diagnosing a subarachnoid haemorrhage? Clin Chem Lab Med 2013, 51:2073-2086.

14. Agid R, Andersson T, Almqvist $H$, Willinsky RA, Lee SK, terBrugge KG, Farb Rl, Söderman M: Negative CT angiography findings in patients with spontaneous subarachnoid hemorrhage: when is digital subtraction angiography still needed? AJNR Am J Neuroradiol 2010 31:696-705.

15. McCormack RF, Hutson A: Can computed tomography angiography of the brain replace lumbar puncture in the evaluation of acute-onset headache after a negative noncontrast cranial computed tomography scan? Acad Emerg Med 2010, 17:444-451.

16. da Rocha AJ, da Silva CJ, Gama HP, Baccin CE, Braga FT, Cesare Fde A, Veiga JC: Comparison of magnetic resonance imaging sequences with computed tomography to detect low-grade subarachnoid hemorrhage. J Comput Assist Tomogr 2006, 30:295-303.

17. Prestigiacomo CJ, Sabit A, He W, Jethwa P, Gandhi C, Russin J: Three dimensional $\mathrm{CT}$ angiography versus digital subtraction angiography in the detection of intracranial aneurysms in subarachnoid hemorrhage. J Neurointerv Surg 2010, 2:385-389.

18. Lu L, Zhang LJ, Poon CS, Wu SY, Zhou CS, Luo S, Wang M, Lu GM: Digital subtraction $\mathrm{CT}$ angiography for detection of intracranial aneurysms: comparison with three-dimensional digital subtraction angiography. Radiology 2012, 262:605-612.

19. Menke J, Larsen J, Kallenberg K: Diagnosing cerebral aneurysms by computed tomographic angiography: meta-analysis. Ann Neurol 2011, 69:646-654.

20. Westerlaan HE, van Dijk JM, der Weide MC J, de Groot JC, Groen RJ, Mooij JJ, Oudkerk M: Intracranial aneurysms in patients with subarachnoid hemorrhage: $\mathrm{CT}$ angiography as a primary examination tool for diagnosis - systematic review and meta-analysis. Radiology 2011, 258:134-145.

21. Xing W, Chen W, Sheng J, Peng Y, Lu J, Wu X, Tian J: Sixty-four-row multislice computed tomographic angiography in the diagnosis and characterization of intracranial aneurysms - comparison with 3D rotational angiography. World Neurosurg 2011, 76:105-113.

22. Wang H, Li W, He H, Luo L, Chen C, Guo Y: 320-Detector row CT angiography for detection and evaluation of intracranial aneurysms: comparison with conventional digital subtraction angiography. Clin Radiol 2013, 68:e15-e20.

23. Hayashida E, Sasao A, Hirai T, Hamasaki K, Nishi T, Utsunomiya D, Oda S, Iryo $Y$, Urata J, Yamashita Y: Can sufficient preoperative information of intracranial aneurysms be obtained by using 320-row detector CT angiography alone? J.jp J Radiol 2013, 31:600-607.

24. Bakker NA, Groen RJ, Foumani M, Uyttenboogaart M, Eshghi OS, Metzemaekers JD, Lammers N, Luijckx GJ, Van Dijk JM: Repeat digital subtraction angiography after a negative baseline assessment in nonperimesencephalic subarachnoid hemorrhage: a pooled data meta-analysis. J Neurosurg 2014, 120:99-103.

25. Sailer AMH, Wagemans BAJM, Nelemans PJ, de Graaf R, van Zwam WH: Diagnosing intracranial aneurysms with MR angiography: systematic review and meta-analysis. Stroke 2013, 45:119-126.

26. Frontera JA, Fernandez A, Schmidt JM, Claassen J, Wartenberg KE, Badjatia N, Connolly ES, Mayer SA: Defining vasospasm after subarachnoid hemorrhage: what is the most clinically relevant definition? Stroke 2009, 40:1963-1968.

27. Vergouwen MD, Vermeulen M, van Gijn J, Rinkel GJ, Wijdicks EF, Muizelaar JP, Mendelow AD, Juvela S, Yonas H, Terbrugge KG, Macdonald RL, Diringer MN, Broderick JP, Dreier JP, Roos YB: Definition of delayed cerebral ischemia after aneurysmal subarachnoid hemorrhage as an outcome event in clinical trials and observational studies: proposal of a multidisciplinary research group. Stroke 2010, 41:2391-2395.

28. Vergouwen MDI, llodigwe D, Macdonald RL: Cerebral infarction after subarachnoid hemorrhage contributes to poor outcome by vasospasm-dependent and -independent effects. Stroke 2011, 42:924-929.

29. Rosenberg NF, Liebling SM, Kosteva AR, Maas MB, Prabhakaran S, Naidech AM: Infarct volume predicts delayed recovery in patients with subarachnoid hemorrhage and severe neurological deficits. Neurocrit Care 2013, 19:293-298.

30. Dhar R, Scalfani MT, Blackburn S, Zazulia AR, Videen T, Diringer M: Relationship between angiographic vasospasm and regional hypoperfusion in aneurysmal subarachnoid hemorrhage. Stroke 2012, 43:1788-1794.

31. Macdonald RL: Delayed neurological deterioration after subarachnoid haemorrhage. Nat Rev Neurol 2014, 10:44-58.

32. Participants in the International Multi-disciplinary Consensus Conference on the Critical Care Management of Subarachnoid Hemorrhage, Washington CW, Zipfel GJ: Detection and monitoring of vasospasm and delayed cerebral ischemia: a review and assessment of the literature. Neurocrit Care 2011, 15:312-317.

33. Sloan MA, Alexandrov AV, Tegeler CH, Spencer MP, Caplan LR, Feldmann E, Wechsler LR, Newell DW, Gomez CR, Babikian VL, Lefkowitz D, Goldman RS, Armon C, Hsu CY, Goodin DS: Assessment: transcranial Doppler ultrasonography: report of the Therapeutics and Technology Assessment 
Subcommittee of the American Academy of Neurology. Neurology 2004, 62:1468-1481.

34. Lysakowski C, Walder B, Costanza MC, Tramèr MR: Transcranial Doppler versus angiography in patients with vasospasm due to a ruptured cerebral aneurysm: a systematic review. Stroke 2001, 32:2292-2298.

35. Otawara YY, Ogasawara KK, Ogawa AA, Sasaki MM, Takahashi KK: Evaluation of vasospasm after subarachnoid hemorrhage by use of multislice computed tomographic angiography. Neurosurgery 2002, 51:939-942. discussion 942-943.

36. Yoon DYD, Choi CSC, Kim KHK, Cho B-MB: Multidetector-row CT angiography of cerebral vasospasm after aneurysmal subarachnoid hemorrhage: comparison of volume-rendered images and digital subtraction angiography. AJNR Am J Neuroradiol 2006, 27:370-377.

37. Wintermark M, Ko NU, Smith WS, Liu S, Higashida RT, Dillon WP: Vasospasm after subarachnoid hemorrhage: utility of perfusion $\mathrm{CT}$ and $\mathrm{CT}$ angiography on diagnosis and management. AJNR Am J Neuroradiol 2006, 27:26-34.

38. Mir DI, Gupta A, Dunning A, Puchi L, Robinson CL, Epstein HA, Sanelli PC: CT perfusion for detection of delayed cerebral ischemia in aneurysmal subarachnoid hemorrhage: a systematic review and meta-analysis. AJNR Am J Neuroradiol 2014, 35:866-871.

39. Cremers CHP, van der Schaaf IC, Wensink E, Greving JP, Rinkel GJ, Velthuis BK, Vergouwen MD: CT perfusion and delayed cerebral ischemia in aneurysmal subarachnoid hemorrhage: a systematic review and meta-analysis. J Cereb Blood Flow Metab 2014, 34:200-207.

40. van der Schaaf I, Wermer MJ, van der Graaf Y, Velthuis BK, van de Kraats Cl, Rinkel GJ: Prognostic value of cerebral perfusion-computed tomography in the acute stage after subarachnoid hemorrhage for the development of delayed cerebral ischemia. Stroke 2006, 37:409-413.

41. Dankbaar JW, de Rooij NK, Rijsdijk M, Velthuis BK, Frijns CJ, Rinkel GJ, van der Schaaf IC: Diagnostic threshold values of cerebral perfusion measured with computed tomography for delayed cerebral ischemia after aneurysmal subarachnoid hemorrhage. Stroke 2010, 41:1927-1932.

42. Sanelli PC, Ugorec I, Johnson CE, Tan J, Segal AZ, Fink M, Heier LA Tsiouris AJ, Comunale JP, John M, Stieg PE, Zimmerman RD, Mushlin Al: Using quantitative $\mathrm{CT}$ perfusion for evaluation of delayed cerebral ischemia following aneurysmal subarachnoid hemorrhage. AJNR Am J Neuroradiol 2011, 32:2047-2053.

43. Harrigan MR, Magnano CR, Guterman LR, Hopkins LN: Computed tomographic perfusion in the management of aneurysmal subarachnoid hemorrhage: new application of an existent technique. Neurosurgery 2005, 56:304-317.

44. Sviri GE, Britz GW, Lewis DH, Newell DW, Zaaroor M, Cohen W: Dynamic perfusion computed tomography in the diagnosis of cerebral vasospasm. Neurosurgery 2006, 59:319-325.

45. Pham M, Johnson A, Bartsch AJ, Lindner C, Müllges W, Roosen K, Solymosi L, Bendszus M: CT perfusion predicts secondary cerebral infarction after aneurysmal subarachnoid hemorrhage. Neurology 2007, 69:762-765

46. Lagares A, Cicuendez M, Ramos A, Salvador E, Alén JF, Kaen A, Jiménez-Roldán L, Millán JM: Acute perfusion changes after spontaneous SAH: a perfusion CT study. Acta Neurochir (Wien) 2012, 154:405-411.

47. van der Schaaf I, Wermer MJ, van der Graaf Y, Hoff RG, Rinkel GJE, Velthuis BK: CT after subarachnoid hemorrhage: relation of cerebral perfusion to delayed cerebral ischemia. Neurology 2006, 66:1533-1538.

48. Rijsdijk M, van der Schaaf IC, Velthuis BK, Wermer MJ, Rinkel GJE: Global and focal cerebral perfusion after aneurysmal subarachnoid hemorrhage in relation with delayed cerebral ischemia. Neuroradiology 2008, 50:813-820

49. Sanelli PC, Anumula N, Johnson CE, Comunale JP, Tsiouris AJ, Riina H, Segal AZ, Stieg PE, Zimmerman RD, Mushlin Al: Evaluating CT perfusion using outcome measures of delayed cerebral ischemia in aneurysmal subarachnoid hemorrhage. AJNR Am J Neuroradiol 2013, 34:292-298.

50. Chai W-NW, Sun X-CX, LV F-JF, Wan BB, Jiang LL: Clinical study of changes of cerebral microcirculation in cerebral vasospasm after $\mathrm{SAH}$. Acta Neurochir Suppl 2011, 110(Pt 1):225-228.

51. Lanterna LA, Lunghi A, Martchenko S, Gritti P, Bonaldi G, Biroli F: Cerebral watershed hypoperfusion in subarachnoid hemorrhage: computed tomography perfusion analysis. J Neurosurg 2011, 114:961-968.

52. Hickmann AK, Langner S, Kirsch M, Baldauf J, Müller C, Khaw A, Schroeder $H W$ : The value of perfusion computed tomography in predicting clinically relevant vasospasm in patients with aneurysmal subarachnoid hemorrhage. Neurosurg Rev 2013, 36:267-278. discussion 278.

53. Kanazawa R, Kato M, Ishikawa K, Eguchi T, Teramoto A: Convenience of the computed tomography perfusion method for cerebral vasospasm detection after subarachnoid hemorrhage. Surg Neurol 2007, 67:604-611.

54. Killeen RP, Mushlin Al, Johnson CE, Comunale JP, Tsiouris AJ, Delaney H, Dunning A, Sanelli PC: Comparison of CT perfusion and digital subtraction angiography in the evaluation of delayed cerebral ischemia. Acad Radiol 2011, 18:1094-1100.

55. Tang G, Cawley CM, Dion JE, Barrow DL: Intraoperative angiography during aneurysm surgery: a prospective evaluation of efficacy. J Neurosurg 2002, 96:993-999.

56. Chalouhi N, Theofanis T, Jabbour P, Dumont AS, Fernando Gonzalez L, Starke RM, Dalyai RT, Hann S, Rosenwasser R, Tjoumakaris S: Safety and efficacy of intraoperative angiography in craniotomies for cerebral aneurysms and arteriovenous malformations: a review of 1093 consecutive cases. Neurosurgery 2012, 71:1162-1169.

57. Molyneux A, Kerr R, Stratton I, Sandercock P, Clarke M, Shrimpton J, Holman R, International Subarachnoid Aneurysm Trial (ISAT) Collaborative Group: International Subarachnoid Aneurysm Trial (ISAT) of neurosurgical clipping versus endovascular coiling in 2143 patients with ruptured intracranial aneurysms: a randomised trial. Lancet 2002, 360:1267-1274

58. Molyneux AJ, Kerr RS, Yu LM, Clarke M, Sneade M, Yarnold JA, Sandercock P, International Subarachnoid Aneurysm Trial (ISAT) Collaborative Group: International subarachnoid aneurysm trial (ISAT) of neurosurgical clipping versus endovascular coiling in 2143 patients with ruptured intracranial aneurysms: a randomised comparison of effects on survival, dependency, seizures, rebleeding, subgroups, and aneurysm occlusion. Lancet 2005, 366:809-817.

59. Campi A, Ramzi N, Molyneux AJ, Summers PE, Kerr RS, Sneade M, Yarnold JA, Rischmiller J, Byrne JV: Retreatment of ruptured cerebral aneurysms in patients randomized by coiling or clipping in the International Subarachnoid Aneurysm Trial (ISAT). Stroke 2007, 38:1538-1544

60. Mitchell $P$, Kerr R, Mendelow AD, Molyneux A: Could late rebleeding overturn the superiority of cranial aneurysm coil embolization over clip ligation seen in the International Subarachnoid Aneurysm Trial? J Neurosurg 2008, 108:437-442.

61. van Amerongen MJ, Boogaarts HD, de Vries J, Verbeek AL, Meijer FJ, Prokop M, Bartels RH: MRA versus DSA for follow-up of coiled intracranial aneurysms: a meta-analysis. AJNR Am J Neuroradiol 2013, [Epub ahead of print]

62. Lee JH, Kim SJ, Cha J, Kim HJ, Lee DH, Choi CG, Lee HK, Suh DC, Ahn JS: Postoperative multidetector computed tomography angiography after aneurysm clipping: comparison with digital subtraction angiography. J Comput Assist Tomogr 2005, 29:20-25.

63. Dehdashti AR, Binaghi S, Uske A, Regli L: Comparison of multislice computerized tomography angiography and digital subtraction angiography in the postoperative evaluation of patients with clipped aneurysms. J Neurosurg 2006, 104:395-403.

64. Pechlivanis I, Koenen D, Engelhardt M, Scholz M, Koenig M, Heuser L, Harders A, Schmieder K: Computed tomographic angiography in the evaluation of clip placement for intracranial aneurysm. Acta Neurochir 2008, 150:669-676.

65. Watanabe Y, Kashiwagi N, Yamada N, Higashi M, Fukuda T, Morikawa S, Onishi $Y$, lihara $K$, Miyamoto $S$, Naito H: Subtraction 3D CT angiography with the orbital synchronized helical scan technique for the evaluation of postoperative cerebral aneurysms treated with cobalt-alloy clips. AJNR Am J Neuroradiol 2008, 29:1071-1075.

66. Uysal E, Ozel A, Erturk SM, Kırdar Ö, Basak M: Comparison of multislice computed tomography angiography and digital subtraction angiography in the detection of residual or recurrent aneurysm after surgical clipping with titanium clips. Acta Neurochir (Wien) 2009, 151:131-135.

67. Gerardin E, Tollard E, Derrey S, Langlois O, Dacher JN, Douvrin F, Freger P, Proust F: Usefulness of multislice computerized tomographic angiography in the postoperative evaluation of patients with clipped aneurysms. Acta Neurochir (Wien) 2010, 152:793-802.

68. Bharatha A, Yeung R, Durant D, Fox AJ, Aviv RI, Howard P, Thompson AL, Bartlett ES, Symons SP: Comparison of computed tomography angiography with digital subtraction angiography in the assessment of clipped intracranial aneurysms. J Comput Assist Tomogr 2010, 34:440-445. 
69. Zachenhofer I, Cejna M, Schuster A, Donat M, Roessler K: Image quality and artefact generation post-cerebral aneurysm clipping using a 64-row multislice computer tomography angiography (MSCTA) technology: a retrospective study and review of the literature. Clin Neurol Neurosurg 2010, 112:386-391.

70. van der Schaaf IC, Velthuis BK, Wermer MJ, Frenkel NJ, Majoie CB, Witkamp TD, de Kort G, Freling NJ, Rinkel GJ, ASTRA Study Group: Multislice computed tomography angiography screening for new aneurysms in patients with previously clip-treated intracranial aneurysms: feasibility, positive predictive value, and interobserver agreement. J Neurosurg 2006, 105:682-688.

71. Psychogios MN, Scholz B, Rohkohl C, Kyriakou Y, Mohr A, Schramm P, Wachter D, Wasser $K$, Knauth M: Impact of a new metal artefact reduction algorithm in the noninvasive follow-up of intracranial clips, coils, and stents with flat-panel angiographic CTA: initial results. Neuroradiology 2013, 55:813-818.

72. Prell D, Kyriakou Y, Struffert T, Dorfler A, Kalender WA: Metal artifact reduction for clipping and coiling in interventional C-Arm CT. AJNR Am J Neuroradiol 2010, 31:634-639.

73. Khursheed F, Rohlffs F, Suzuki S, Kim DH, Ellmore TM: Artifact quantification and tractography from $3 \mathrm{~T} \mathrm{MRI}$ after placement of aneurysm clips in subarachnoid hemorrhage patients. BMC Med Imaging 2011, 11:19.

74. Hadjivassiliou M, Tooth CL, Romanowski CA, Byrne J, Battersby RD, Oxbury S, Crewswell CS, Burkitt E, Stokes NA, Paul C, Mayes AR, Sagar HJ: Aneurysmal SAH cognitive outcome and structural damage after clipping or coiling. Neurology 2001, 56:1672-1677.

75. Kivisaari RP, Salonen O, Servo A, Autti T, Hernesniemi J, Ohman J: MR imaging after aneurysmal subarachnoid hemorrhage and surgery: a long-term follow-up study. AJNR Am J Neuroradiol 2001, 22:1143-1148.

76. Bendel $P$, Koivisto $T$, Könönen $M$, Hänninen $T$, Hurskainen $H$, Saari $T$, Vapalahti M, Hernesniemi J, Vanninen R: MR imaging of the brain 1 year after aneurysmal subarachnoid hemorrhage: randomized study comparing surgical with endovascular treatment. Radiology 2008, 246:543-552.

77. Koivisto T, Vanninen R, Hurskainen H, Saari T, Hernesniemi J, Vapalahti M: Outcomes of early endovascular versus surgical treatment of ruptured cerebral aneurysms: A prospective randomized study. Stroke 2000, 31:2369-2377.

78. Bendel $P$, Koivisto $T$, Hänninen $T$, Kolehmainen A, Könönen $M$, Hurskainen $H$ Pennanen C, Vanninen R: Subarachnoid hemorrhage is followed by temporomesial volume loss: MRI volumetric study. Neurology 2006, 67:575-582

79. Bendel P, Koivisto T, Niskanen E, Könönen M, Aikiä M, Hänninen T, Koskenkorva P, Vanninen R: Brain atrophy and neuropsychological outcome after treatment of ruptured anterior cerebral artery aneurysms: a voxel-based morphometric study. Neuroradiology 2009, 51:711-722.

80. Bendel P, Koivisto T, Aikiä M, Niskanen E, Könönen M, Hänninen T, Vanninen R: Atrophic enlargement of CSF volume after subarachnoid hemorrhage: correlation with neuropsychological outcome. AJNR Am J Neuroradiol 2010, 31:370-376.

81. Shimoda M, Hoshikawa K, Shiramizu H, Oda S, Yoshiyama M, Osada T, Matsumae M: Early infarction detected by diffusion-weighted imaging in patients with subarachnoid hemorrhage. Acta Neurochir (Wien) 2010, 152:1197-1205.

82. Hadeishi HH, Suzuki AA, Yasui NN, Hatazawa JJ, Shimosegawa EE: Diffusion-weighted magnetic resonance imaging in patients with subarachnoid hemorrhage. Neurosurgery 2002, 50:741-748.

83. Weidauer S, Vatter H, Beck J, Raabe A, Lanfermann H, Seifert V, Zanella F: Focal laminar cortical infarcts following aneurysmal subarachnoid haemorrhage. Neuroradiology 2007, 50:1-8.

84. Sato $K$, Shimizu $H$, Fujimura $M$, Inoue $T$, Matsumoto $Y$, Tominaga $T$ : Acute-stage diffusion-weighted magnetic resonance imaging for predicting outcome of poor-grade aneurysmal subarachnoid hemorrhage. J Cereb Blood Flow Metab 2010, 30:1110-1120.

85. Wartenberg KE, Sheth SJ, Michael Schmidt J, Frontera JA, Rincon F, Ostapkovich N, Fernandez L, Badjatia N, Sander Connolly E, Khandji A, Mayer SA: Acute ischemic injury on diffusion-weighted magnetic resonance imaging after poor grade subarachnoid hemorrhage. Neurocrit Care 2010, 14:407-415.

86. Frontera JA, Ahmed W, Zach V, Jovine M, Tanenbaum L, Sehba F, Patel A, Bederson JB, Gordon E: Acute ischaemia after subarachnoid haemorrhage, relationship with early brain injury and impact on outcome: a prospective quantitative MRI study. I Neurol Neurosurg Psychiatry 2014, [Epub ahead of print]

87. Ogawa S, Lee TM, Kay AR, Tank DW: Brain magnetic resonance imaging with contrast dependent on blood oxygenation. Proc Natl Acad Sci U S A 1990, 87:9868-9872.

88. Calautti C, Baron J-C: Functional neuroimaging studies of motor recovery after stroke in adults: a review. Stroke 2003, 34:1553-1566.

89. McDowell MM, Kellner CP, Barton SM, Mikell CB, Sussman ES, Heuts SG, Connolly ES: The role of advanced neuroimaging in intracerebral hemorrhage. Neurosurg Focus 2013, 34:E2.

90. Ellmore TM, Rohlffs F, Khursheed F: FMRI of working memory impairment after recovery from subarachnoid hemorrhage. Front Neurol 2013, 4:179-179.

91. Martin WR, Baker RP, Grubb RL, Raichle ME: Cerebral blood volume, blood flow, and oxygen metabolism in cerebral ischaemia and subarachnoid haemorrhage: an in-vivo study using positron emission tomography. Acta Neurochir (Wien) 1984, 70:3-9.

92. Powers WJ, Grubb RL, Baker RP, Mintun MA, Raichle ME: Regional cerebral blood flow and metabolism in reversible ischemia due to vasospasm. Determination by positron emission tomography. J Neurosurg 1985, 62:539-546.

93. Hino A, Mizukawa N, Tenjin H, Imahori Y, Taketomo S, Yano I, Nakahashi H, Hirakawa K: Postoperative hemodynamic and metabolic changes in patients with subarachnoid hemorrhage. Stroke 1989, 20:1504-1510.

94. Sarrafzadeh AS, Nagel A, Czabanka M, Denecke T, Vajkoczy P, Plotkin M: Imaging of hypoxic-ischemic penumbra with (18)F-fluoromisonidazole PET/CT and measurement of related cerebral metabolism in aneurysmal subarachnoid hemorrhage. J Cereb Blood Flow Metab 2010, 30:36-45.

95. Jost SC, Diringer MN, Zazulia AR, Videen TO, Aiyagari V, Grubb RL, Powers WJ: Effect of normal saline bolus on cerebral blood flow in regions with low baseline flow in patients with vasospasm following subarachnoid hemorrhage. J Neurosurg 2005, 103:25-30

96. Dhar R, Zazulia AR, Videen TO, Zipfel GJ, Derdeyn CP, Diringer MN: Red blood cell transfusion increases cerebral oxygen delivery in anemic patients with subarachnoid hemorrhage. Stroke 2009, 40:3039-3044.

97. Dhar R, Scalfani MT, Zazulia AR, Videen TO, Derdeyn CP, Diringer MN: Comparison of induced hypertension, fluid bolus, and blood transfusion to augment cerebral oxygen delivery after subarachnoid hemorrhage. J Neurosurg 2012, 116:648-656.

98. van Gijn J, Hijdra A, Wijdicks EF, Vermeulen M, van Crevel H: Acute hydrocephalus after aneurysmal subarachnoid hemorrhage. J Neurosurg 1985, 63:355-362.

doi:10.1186/s13054-014-0557-2

Cite this article as: de Oliveira Manoel et al: Aneurysmal subarachnoid haemorrhage from a neuroimaging perspective. Critical Care 2014 18:557. 